\title{
MEASURING THE ADEQUACY OF RETIREMENT SAVINGS
}

By J ohn BurnetT, ${ }^{1}$ Kevin Davis, 2, 3, 4 Carsten MuraWSKI, ${ }^{2}$ Roger Wilkins, 5

AND NICHOLAS WILKINSON ${ }^{1}$

1 Willis Towers Watson, Sydney, Australia

2 Department of Finance, The University of Melbourne, Melbourne, Australia

3 Department of Finance, Monash University, Melbourne, Australia

4 Australian Centre for Financial Studies, Melbourne, Australia

5 Melbourne Institute for Applied Economic and Social Research,

The University of Melbourne, Melbourne, Australia

*Correspondence to: Carsten Murawski, Department of Finance, The

University of Melboume, VIC 3010, Australia (carstenm@unimelb.edu.au).

Note: This paper uses data from the Household, Income, and Labour

Dynamics in Australia (HILDA) Survey. The survey was initiated and is funded

by the Australian Government Department of Social Services (DSS), and is managed by the Melbourne Institute of Applied Economic and Social

Research. The findings and views based on these data should not be

attributed to either the DSS or to our employers.

$(\rightarrow)$

Abstract This paper introduces four metrics for quantifying the adequacy of retirement savings, taking into account all major sources of retirement income.

We then apply them to projections of expected future retirement income streams of a representative sample of the Australian population aged 40 and above. We find that omitting one or more pillars of saving significantly biases estimates of retirement savings adequacy. We also find that the four metrics are only weakly correlated with key commonly used indicators of financial well-being, in particular current income and net worth. Our analysis also points to several shortcomings of the widely used income replacement ratio as an indicator of savings adequacy.

J EL Codes: D14, D91, P46

This is the author manuscript accepted for publication and has undergone full peer review but has not been through the copyediting, typesetting, pagination and proofreading process, which may lead to differences between this version and the Version record. Please cite this article as doi:10.1111/ roiw.12307. 
Keywords: retirement savings, financial literacy, life-cycle consumption and savings, household finance

\section{Introduction}

There seems to be widespread agreement that most people do not save enough for their retirement (Bernheim, 1992; Choi et al., 2004; Munnell et al., 2006; Skinner, 2007; Beshears et al., 2009; Benarti, 2012). While there is a multiplicity of normative models of life-cycle consumption and saving, many of these models are difficult to implement in practice, even for finance professionals (Lusardi and Mitchell, 2007; Skinner, 2007). This means that there is no agreement on how much saving is enough.

The most widely used measure to assess adequacy of retirement savings is the income replacement ratio (Purcell, 2012), the ratio of post-retirement income 1 to pre-retirement income. As a rule of thumb, a replacement ratio of about 80 percent is often considered adequate (Benarti, 2012). However, the income replacement ratio has some shortcomings.

First, while it may be a useful reference point when approaching retirementand Purcell (2012) notes that many users of this metric use income figures just prior to retirement-it is less informative and useful for those decades away from retirement. Income is typically not constant over the working life cycle. Using current income will give estimates of adequate post-retirement income that will be sensitive to the point in the life cycle at which it is evaluated. Post-retirement income needs of younger people will be systematically underestimated, and estimating by how much the replacement ratio should be adjusted to reflect higher income and consumption habits near retirement is problematic.

Second, the income replacement ratio ignores the fact that the actual level of consumption implied varies with income level. For example, people with low pre-retirement income levels may often be able to achieve a high income replacement ratio, largely due to social security payments such as pensions and various other forms of post-retirement income support But this is a much 
lower level of consumption than that of people in high-income groups, who often have a much lower income replacement ratio but are better off in retirement

Third, there is robust evidence that many people struggle with interpreting information such as the income replacement ratio and hence it may not be very effective in communicating savings adequacy (Reyna and Brainerd, 2007). We believe that our suggested metrics are better suited for communicating savings adequacy to individuals at stages of their working life where behavioral changes can be made that have significant effects on retirement income adequacy.

Another severe shortcoming of existing assessments of retirement savings adequacy is the focus on retirement savings accounts, such as $401(\mathrm{k})$ accounts in the United States (U.S.), sometimes additionally taking into account government pensions. The retirement income of the majority of individuals and households is, however, drawn from a wider set of sources that includes property and financial assets other than retirement savings accounts. Thus, many existing assessments of savings adequacy likely paint an imperfect picture of adequacy. Moreover, ignoring these other sources of retirement income likely also leads to misrepresentation of the total risk profile of retirement savings and income.

Partly as a consequence of the lack of agreement on what constitutes an adequate level of retirement savings, financial advice is often based on rules of thumb. One is the widely used " 10 percent rule," prescribing that savings should equal 10 percent of after-tax income (Benarti, 2012). Such rules of thumb ignore the large heterogeneity in individual circumstances (including age-related consumption needs) and in many cases will lead to savings outcomes that are either too high or too low.

At the same time, it has been widely documented that retirement savings vary significantly even among people with similar income levels (Bernheim et al., 2001). Savings behavior is affected by a large number of factors, including 
socioeconomic, cognitive, and other psychological factors (Bernheim and Rangel, 2005; Skinner, 2007). A "one-size-fits-all" approach (such as the "10 percent rule"), either to determining optimal savings behavior or to the development of policy strategies (such as information provision and advice) to improve savings, is therefore likely to be inappropriate.

Insufficiency of retirement savings is one of the more important economic, social, and political global challenges of our time, with significant consequences at both the individual and societal level. These include the risk of more widespread poverty among the elderly and greater demands for various forms of govemment social assistance, increasing the likelihood of fiscal imbalances. Indeed, the ageing of populations and underfunding of retirement is argued by some to pose a major threat to global financial stability (IMF, 2012).

For policy-makers committed to a system of wide-scale self-funded retirement-reflected globally in increasingly common "defined contribution" (accumulation) private pension plans-it is important to have a set of meaningful measures and to diagnose the extent and nature of any inadequacy of retirement savings. It is of course also important to develop effective means to assist individuals to implement appropriate savings targets, for example by communicating inadequacy to people with the aim for people to take action and by adjusting the institutional environment accordingly (Bènarti, 2012).

In this paper, we propose four metrics quantifying the adequacy of retirement savings, applicable and informative during an individual's working years. Two of the metrics express adequacy in terms of consumption levels, the first measuring projected consumption levels during retirement and the second measuring the shortfall relative to a target consumption level. The other two metrics express adequacy in terms of the number of years in retirement that an adequate consumption level can be maintained, the first measuring the projected age at which savings will run out and the second measuring the difference between this age and life expectancy. For both types of measures, 
our discussion focuses primarily on the latter-mentioned metrics, given our view that these representations are likely to be more informative and relevant to the general population.?

Importantly, our metrics reflect key personal circumstances as well as all pillars of retirement savings (World Bank, 2008), that is, government pension and social security payments, compulsory and voluntary retirement savings, and other household assets. We believe that these metrics are a meaningful indicator of savings adequacy and that they can be effective in communicating savings adequacy to individuals to improve their retirement savings behavior and to alert policy-makers to both the extent and nature of inadequate savings.

We estimate values of our metrics of savings adequacy for a representative sample of the Australian population. We find that omitting one or more of the "pillars" of retirement savings leads to significant underestimation of consumption levels during retirement, particularly among those with higher levels of disposable income and net worth. Moreover, we find that saving at the compulsory superannuation (private pension) contribution rate $(9.25$ percent of wages and salaries at the time of this research, currently 9.5 percent) during a significant part of working life will not be sufficient to achieve an adequate level of consumption during retirement for many in our sample. Indeed, reliance solely on saving at this rate-that is, assuming no government pension support-generates a median consumption level during retirement far below the relative poverty line. For many Australians, the superannuation system cannot be expected to replace the governmentprovided Age Pension (as is sometimes assumed in policy debate), but to be a supplement.

Our statistical analyses also accord with the arguments expressed earlier in suggesting that the income replacement ratio has significant limitations as an indicator of retirement savings adequacy. Most importantly, the income replacement ratio tends to be higher for low-income groups and lower for high-income groups, despite the latter group having higher consumption 
levels. We find that it has very low correlation with our preferred metrics. This suggests that the income replacement ratio should at least be supplemented by other measures of savings adequacy to obtain a more comprehensive view of income or consumption during retirement, a point to which we will return at the end of this paper.

We also find that commonly used indicators of financial well-being such as current household income, retirement savings account balance, and net worth are not necessarily good proxies for adequacy of retirement savings, and more comprehensive metrics such as the ones we propose in this paper should be considered.

The remainder of the paper is structured as follows. In Section 2, we consider the question of how retirement savings targets are determined and how we project future retirement income. Because the projection methods used need to take into account institutional features of the retirement income system under consideration, Section 2 also includes a brief description of the Australian situation. Section 3 provides a brief overview of the HILDA Survey data that we use for making projections. It explains how the particular subsample of respondents was chosen and how problematic issues such as distinguishing between individual and household circumstances were addressed. Section 4 presents the results of our projections, which outline the extent of shortfalls in projected retirement income from a target level deemed as "adequate," using a widely accepted, publicly available measure for both singles and couples. Section 4 also examines the extent to which our four chosen metrics of retirement savings adequacy correlate with each other, and how well they correlate with other adequacy metrics and with key indicators of financial well-being. Section 5 summarizes our findings and discusses limitations of our metrics as well as their suitability in public policy information campaigns.

\section{Defining and Estimating Adequacy}


Assessment of adequacy of current level of retirement savings during working years requires both the determination of the target level of income or consumption in retirement, and the calculation of the projected income or consumption in retirement.

\subsection{Setting Savings Targets}

In this section, we consider how to set retirement savings targets. There appear to be two main types of contenders for defining income or consumption targets. 3 The first type defines target retirement wealth by reference to a desired "replacement ratio," most commonly expressed as a desired ratio of post-retirement income or consumption to pre-retirement income or consumption. The savings target is that level of wealth which will enable an income or consumption stream in retirement equal to some proportion of pre-retirement employment income or consumption. 4 Typically, an average target replacement ratio in the region of 70-80 percent is assumed (with the ratio often decreasing as pre-retirement income increases), reflecting the fact that changed consumption needs, a shift from accumulation (savings) to decumulation mode, and different tax circumstances in retirement will reduce the income level needed to maintain a similar lifestyle level (Munnell et al., 2011).

Another measure of this kind is the "replacement wealth ratio." Here, the target is the level of wealth at retirement required to fund a certain level of income during retirement, expressed as a multiple of pre-retirement income (Booth and Yakoubov, 2000; Basu and Drew, 2010). A replacement wealth ratio of six to eight times pre-retirement income is typically considered adequate (Basu and Drew, 2010). The replacement wealth ratio does not map one-to-one to the income replacement ratio because the mapping between the two measures depends on the (real) rate of return on retirement savings.

The replacement ratio approach takes account of different income levels in the population and the likelihood of "habit formation" in consumption and lifestyle preferences, such that wealthier individuals are assumed to have higher retirement consumption ambitions than the less wealthy (Munnell et 
al., 2011). On the other hand, it is difficult, particularly for younger people, to predict income and consumption levels long into the future, which makes any replacement ratio approach difficult to implement as a guide to adequacy of current retirement savings. Moreover, given the "habit formation" rationale for the approach, presumably what is required is a measure of permanent income, or at least multi-year income. The approach also implicitly assumes that pre-retirement income is "adequate," which is not universally true.

The adequacy measure that is most appropriate depends on the goal of measuring adequacy. If the goal is to measure adequacy against a fixed (universal) living standard, then income replacement ratios are not appropriate. In such a case, it is more critical from a policy perspective to assess whether people are meeting certain levels of living standards. However, if the goal is to achieve a living standard that is closely related to the current standard of living, then the income replacement ratio may be a more appropriate indicator. $.5 \mathrm{~A}$ blended approach, combining a replacement ratio approach tapering at higher incomes and subject to a minimum floor to address living standards, may also be considered in some circumstances.

We adopt an altemative approach by developing metrics based on achieving a specified level of retirement consumption that are independent of preretirement income levels. This is both simpler and arguably provides for a more tangible estimate of target level of retirement wealth required for individuals unsure of their likely final pre-retirement income. The measure is also consistent with the notion that our interest is in whether individuals can achieve some minimum standard of living in retirement. It has strong parallels with studies of poverty, whereby the focus is on the number of people who do not have an income above a certain (poverty) threshold (see, e.g., OECD, 2008).

A key issue is the specification of target retirement income levels. For the purposes of this paper, we use a benchmark widely used in Australia for adequate retirement income provided by the Association of Superannuation Funds of Australia (ASFA, 2012). The target income levels are $\$ 38,339$ for 
singles and $\$ 52,472$ for couples. 6 These targets are significantly higher than the targets that would be adopted if looking at a poverty level threshold. $?$

Some comfort that these benchmark figures are reasonable is found in the HILDA Survey data that we use. These data indicate that the ASFA target levels are in fact close to the actual mean incomes of retirees in 2010, which were $\$ 37,998$ for singles (median $\$ 23,000$ ) and $\$ 54,358$ for couples (median $\$ 41,136)$. Moreover, they are similar to the median estimates of the level of retirement income deemed necessary by non-retired Australians above age 40 to fund a satisfactory lifestyle ( $\$ 35,000$ and $\$ 50,000$ for singles and couples, respectively), collected in the HILDA Survey.

\subsection{Sources of Retirement Income}

Individuals typically draw retirement income from at least three sources: government pension and social security payments (often referred to as "Pillar $1^{\prime \prime)}$, compulsory retirement savings ("Pillar 2"), and voluntary retirement savings. We split the last category into tax-advantaged retirement savings such as voluntary contributions to retirement savings accounts ("Pillar 3") and other retirement savings ("Pillar 4"). The latter include ordinary savings accounts, securities, life insurance policies, and property investments. While we include all of the four pillars of retirement savings in our estimations, we exclude (as is common practice) the value of the home from retirement savings, assuming that home ownership is maintained until death and that the home is bequeathed to descendants (Skinner, 2007).

These four pillars of retirement savings largely correspond to the five pillars of the World Bank's "Five Pillar Framework" of retirement savings (World Bank, 2008). Our Pillar 1 is similar to the World Bank's non-contributory "zero pillar" (see Figure 1). There is no equivalent of the World Bank's mandatory "first pillar" in Australia and thus our framework does not contain any equivalent. Our Pillars 2 and 3 corresponds to the World Bank's mandatory "second pillar" and voluntary "third pillar," respectively, while our Pillar 4 overlaps with the World Bank's voluntary "third pillar" as well as the nonfinancial "fourth pillar."으 We do not consider informal support (e.g. family 
support) and certain types of formal social programs (e.g. healthcare and housing), which are part of the World Bank's fourth pillar.

\section{[PLACE FIGURE 1 NEAR HERE]}

\subsection{Core Elements of the Australian Retirement Savings System}

Several of the savings pillars, and thus the level of savings required before retirement to achieve a target level of retirement income, depend significantly on the institutional environment, such as tax rates and the nature and level of social security payments. To put the estimation of the four adequacy metrics in this paper in context and to facilitate interpretation of estimation results, we briefly describe the core elements of the Australian retirement saving system.

The first pillar is the Age Pension, a universal flat-rate but means-tested pension payable to retired people over the retirement age, which is currently 65 for both men and women.9 Since 2009, the full Age Pension for singles has been set equal to 27.7 percent of average weekly total earnings of male employees, while the Age Pension for couples is 150 percent of the single rate.

The second pillar is based on compulsory retirement savings accounts, known as superannuation, which in most cases take the form of individual defined contribution (accumulation) accounts. Introduced in 1992, legislation initially specified a minimum employer contribution rate of 3 percent of wages, which was gradually increased up to 9 percent by 2002, where it remained until J uly 2013. Legislation applied when the research took place specified that, starting in f uly 2013 , the minimum contribution rate be gradually increased from 9.25 percent to 12 percent by J uly 2019.10 This increase is reflected in our analyses. Compulsory contribution requirements were initially restricted to employees aged 18-64, but the upper age limit has been gradually increased over time and, as of J uly 2013 , there is no upper age restriction. For most employees, there are significant tax benefits associated with such contributions (with a tax rate of 15 percent applying to contributed income streams, which is increased to 30 percent at higher income levels) and on 
earnings in the fund. (A 15 percent tax rate (10 percent for long-term capital gains) applies on fund earnings during the accumulation phase, and there is zero taxation on earnings in the retirement phase).

The third pillar is based on voluntary contributions to tax-favoured retirement savings accounts (with the same tax benefits that apply to earnings on compulsory contributions). These have a longer history than compulsory contributions, but are now less important than compulsory contributions. The fourth pillar comprises any other savings, such as direct security holdings, property investments, or life insurance policies. We now turn to the projection of retirement savings.

\subsection{Projecting Retirement Savings}

For ease of exposition and the purposes of this paper, we consolidate Pillars 2-4 of retirement savings together into one asset class with a common aftertax rate of return. 11 We assume that during the accumulation phase, these assets, which we denote by $\mathrm{K}$, evolve according to the following nonstochastic process of the generalized form:

$$
K_{t+1}=K_{t}(1+r)+\left((s g+s) w_{t}(1-T)-c\right)\left(1+\frac{r}{2}\right),
$$

with $w_{t+1}=(1+i)(1+f) w_{t}$, where t denotes the year, $r$ denotes the after-tax return on assets, sg denotes the compulsory retirement savings rate, $\mathrm{s}$ denotes the voluntary savings rate, $T$ denotes the tax rate on retirement savings contributions, $c$ denotes administration and insurance costs, w denotes gross wages and salaries, i denotes price inflation, and $f$ denotes real income (wage and salary) growth. $\underline{12}$

During retirement, income is drawn from retirement savings, $K$, as well as any government pension or social security payments, denoted as $p$. The level of government pension and social security payments in any given year during retirement depends on the level of other income and wealth (the so-called income test and assets test within the overall means-testing framework). This means that once the specified retirement age is reached, government pension 
eligibility has to be calculated in that and each subsequent year during retirement based on the level of other income and wealth, and thus the variable $p$ above will not be constant during retirement and will typically depend substantially on the current level of retirement savings $\mathrm{K}$.

We also assume that the consumption pattern is maintained in real terms to ensure that the purchasing power of the retirement income over time is not eroded, that is, retirement income is assumed to increase in line with nominal wage growth (i.e. $(1+i)(1+f))$.

\subsection{Defining Savings Adequacy}

We now define our four metrics of retirement savings adequacy. The first metric is the expected level of real income available post-retirement, for each year until age of life expectancy, given current circumstances such as the level of income and wealth. Importantly, Age Pension payments are meanstested, that is, both eligibility and amount in a given period depend on the levels of private wealth and income in that period. If $\mathrm{K}_{0}$ is private wealth available at the start of retirement for an individual with life expectancy at that date of $\mathrm{T}$ years, we calculate the (real) annuity stream for $\mathrm{T}$ years that can be generated based on $\mathrm{K}_{0}$ and subsequent Age Pension receipts. Let $\mathrm{p}_{\mathrm{t}}$ be pension income received in year $t$, and $k_{t}$ be the drawdown of private wealth in year $\mathrm{t}$. Since $\mathrm{p}_{\mathrm{t}}$ is dependent upon $\mathrm{k}_{\mathrm{t}}$ and $\mathrm{K}_{\mathrm{t}}$ (the remaining private wealth at $\mathrm{t}$, which depends upon $\mathrm{K}_{0}, \mathrm{r}$ (the real rate of return), and $k_{0}, \ldots, k_{t}$ ), we write $\mathrm{p}_{\mathrm{t}}$ as a function of $\mathrm{r}, \mathrm{K}_{0}$, and $k_{0, t} \equiv k_{0}, \ldots, k_{t}$. For convenience, we express this functional relationship as $p_{t}=p_{t}\left(K_{0}, k_{0, t}, r\right)$ and denote the present value at retirement age of that stream of pension receipts as $\mathrm{P}_{0}$. We then solve for the T-year maximum constant real annuity of amount $c=p+k$, such that the value of that annuity $A[c, r, T]=K_{0}+P_{0}$. In other words, we find the real constant consumption stream that can be achieved over the $T$ years of expected lifespan, given initial private wealth $\mathrm{K}_{0}$ and drawdown of that amount according to the schedule that achieves the real constant consumption amount including any pension receipts. We refer to the solution $\hat{c}$ as consumption level. 
Our second metric is the difference between expected cash flow postretirement, $\hat{c}$, as computed above, and the target level of cash flow (based on the ASFA standard), which we denote $\bar{c}$. We denote this metric by $\hat{s}$, that is, $\hat{s}=\hat{c}-\bar{c}$. We call this metric the consumption shortfall. Figure 2 shows the relations between $\bar{c}, \hat{c}$ and $\hat{s}$, which are all measured in real dollar amounts.

\section{[PLACE FIGURE 2 NEAR HERE]}

For our third and fourth metrics, we assume instead that individuals consume at the target rate, $\bar{c}$, for as long as they are able, given initial private wealth $\mathrm{K}_{0}$ and supplemented (where eligible) by Age Pension income receipts. For some individuals, private wealth may be so low as to preclude ever consuming at that rate. In terms of our prior notation, we determine if there are values of $\mathrm{k}_{1}$ such that $k_{1}+p_{1}\left(K_{0}, k_{0,1}, r\right)=\bar{c}$ is feasible. If so, $\mathrm{k}_{1}$ is set to maximize $\mathrm{p}_{1}$ subject to $k_{1}+p_{1}=\bar{c}$. This calculation is sequentially repeated for $k_{2}, k_{3}$, and so on until $k_{\tau}$, when $\bar{c}$ can no longer be achieved due to exhaustion of private wealth. We call $65+\tau$ the run-out age, after which consumption reverts to the level given by the Age Pension. We call the difference between life expectancy $T$ and $65+\tau$ the age gap, which we denote by $\hat{\gamma}$.

The two sets of metrics, consumption level and consumption shortfall on the one hand, and run-out age and age gap on the other, measure retirement savings adequacy along different dimensions (real income versus years). They are obviously closely related, but make different assumptions about consumption in the post-retirement phase. The consumption level and consumption shortfall metrics calculate the level of consumption that can be achieved and the difference between this level and the target level of consumption respectively. These metrics can be expressed in today's dollars to ensure consistency between individuals retining at different points in time and comparability against retirement income targets based on current costs of living. 
The run-out age and age gap metrics assume that individuals immediately commence consuming at the target consumption level upon retirement (if accumulated wealth permits), drawing down retirement savings and using whatever government pension income is available to them. They continue to do so until private retirement savings are exhausted and they are forced to revert to a lower level of consumption equal to the full government pension. Because this involves a different run-down of private retirement savings compared to the consumption metrics, and thus potentially has different implications for government pension receipts over the retirement phase, these two measures will not be perfectly correlated.

\section{The Dataset}

We now turn to estimating the adequacy metrics described in the previous section, based on the individual circumstances of a large set of individuals and households.

\subsection{The HILDA Survey}

Our data come from the HILDA Survey, an Australian household panel study that commenced in 2001, with a nationally representative sample. The survey is conducted annually by face-to-face interview with every household member aged 15 years and over, supplemented by a self-completion questionnaire, also administered to all household members aged 15 years and over (Wooden and Watson, 2007; Summerfield et al., 2012). Annual re-interview rates (the proportion of respondents from one wave who are successfully interviewed in the next) are high, rising from 87 percent in Wave 2 to over 95.5 percent from Wave 5 onwards.

The HILDA Survey is well suited to the study of retirement savings adequacy, collecting comprehensive information on a wide range of relevant topics for a sample representative of the entire population. The topics covered include labor market and education activity, retirement intentions and behavior, income, expenditure, health and disability, subjective well-being, and personal relationships. Most importantly for this study, the HILDA Survey also collects 
detailed information on household assets and debts every 4 years. For each household, information was collected on 11 asset components and seven debt components, which can be combined to calculate the value of retirement savings.

This paper draws on the wealth data collected in 2010 (Wave 10), which contains information on 14,255 individuals over the age of 15 residing in 7,317 households. 13 However, we only report results for the 7,540 individuals aged 40 and above, residing in 5,001 households. These individuals are representative of the $\mathbf{1 0 . 0}$ million people over 40 years who constitute 45.6 percent of the Australian population as atJ une 2010. While in principle it is possible to project retirement savings for individuals younger than 40 years of age, in practice these projections are likely to be much less reliable because of greater uncertainty about future earnings, household composition, homeownership status, and wealth accumulation. The focus of our analysis will be on individuals between age 40 and 64, but we also report estimation results for individuals aged 65 and above as a comparison between the part of our sample below retirement age (65) and above retirement age. All estimates presented in the Results section (Section 4) are computed using population weights to make them representative of the Australian population (Watson, 2012).

Our dataset allows us to address three important issues: (1) we can examine retirement savings in a setting in which all four pillars of retirement savings (government pension, compulsory and voluntary retirement savings, and other savings) have been present for more than 20 years and investigate their relative contributions; (2) employees of the younger age groups in our sample will have generally received contributions of 9 percent (or more) of their wages and salaries to a defined-contribution retirement savings account throughout a significant part of their working lives-that is, we examine a sample in which employees are saving at a rate close to the "10 percent rule" that is often used as a rule of thumb by financial advisors in the U.S. (Benarti, 2012); and (3) the retirement savings system in Australia is in a more mature state than similar defined-contribution pension systems 
elsewhere in the world, and hence our data allow us to investigate issues now with which other countries will be dealing in the near future when their defined-contribution retirement savings grow. 14 The U.S. and the United Kingdom in particular have started down the path of moving away from defined-benefit employer supported benefits toward defined-contribution systems, but this has generally happened later than in Australia. The issue of retirement adequacy and the appropriate level of savings is a more significant issue when the responsibility lies with the individual to save for and manage their own retirement income.

\subsection{Projecting Retirement Income}

To project retirement savings as described in Section 2, we calculate net assets of each household in 2010, our starting date, based on the data available in the HILDA Survey. More specifically, we combine a household's bank accounts, superannuation (retirement savings) accounts, securities (equity, fixed income securities), trust funds, life insurance policies, property investments, and businesses. We exclude the home of the household since we assume that it will be bequeathed or used to finance late-in-life specialist accommodation or aged-care expenses (see Section 4). From total assets, we subtract household debt. This gives us the current value (in 2010) of (net) retirement savings, $K$. The HILDA Survey also collects each household member's wage and salary income, $w$, from which contributions to retirement savings are made, and their age, marital status, and home-ownership status.

In the accumulation phase until the assumed retirement age (65), retirement savings are assumed to evolve according to Equation (1), with the following parameter specifications: asset returns $r=6.4$ percent per annum net of investment tax and asset-based fees prior to retirement and 6.5 percent per annum net of asset-based fees after retirement 15 (consistent with the investment objectives for the typical default investment strategy used by the majority of individuals in their superannuation accounts, as well as with the assumptions used by the Australian regulator in its publicly available calculator at the time of this research); price inflation $\mathrm{i}=2.5$ percent per 
annum (the mid-point of the Reserve Bank of Australia's target range); and real income (wage and salary) growth $f=1$ percent per annum (assumptions used by the Australian regulator in its publicly available calculator). $\underline{16}$ Compulsory superannuation contributions (sg) are set at 9 percent up to 2012 and then increased in line with the legislated changes from 2013 onwards, as the legislation stood at the time of this research. Voluntary superannuation contribution rates ( $\mathrm{s}$ ) are based on levels observed in the HILDA Survey data for 2010, allowing for contributions tax (T) and administration/insurance costs (c) where applicable.

\subsection{Sample Summary Statistics}

The 7,540 individuals in our sample, of whom 4,034 (53.5 percent) are female, reside in 5,001 households. The median and mean ages of our sample members are 56.0 years and 57.8 years, respectively (standard deviation $=12.6$ ). 5,230 (69.35 percent) are married or live in a de facto marriage and 599 ( 7.95 percent) are lone parents. The mean number of children is 0.6. Of all sample members, 2,630 (34.95 percent) did not complete high school, 676 (9.05 percent) completed high school, 2,561 (24.05 percent) obtained other post-secondary school qualification or a diploma, and 1,667 (22.15 percent) have a university degree or higher qualifications. Of these sample members, 4,489 (59.55 percent) live in a major city and 2,001 (26.55 percent) live in inner regional Australia, while 1,048 (13.95 percent) live in remote areas. Furthermore, 3,277 (43.55 percent) of our sample members are fully employed and 2,511 (33.35 percent) are fully retired from the workforce.

Median gross household income is $\$ 77,000$ ( $\$ 97,601$ for sample members aged $40-64$, and $\$ 34,880$ for sample members aged 65 and above). Private sources account for $\mathbf{7 2 . 6}$ percent of gross income received by sample members, although this share differs considerably be age group, declining from 84 percent to 88 percent among those aged $40-59$ to approximately 30 percent among those aged 80 and over. The government pension is an important income source among those aged 65 and over. Among sample 
members aged 65-69, government pensions make up 39 percent of income, rising up to two thirds of income among sample members aged 80 and above. In other words, the government pension is by far the most significant source of retirement income.

Median household disposable income is $\$ 69,644$ and declines in age from the 45-49 age group onwards. Reflecting the effects of adult children moving out of the parental home, median equalized household disposable income peaks later, reaching a high of $\$ 48,991$ in the 55-59 age group age.17

Turning to household wealth, the median of total (gross) household assets in our sample is $\$ 731,000$. Median total assets peak in the $55-59$ age group at $\$ 975,950$, and thereafter declines in age. The dominant asset class across all age groups in our sample is the home (47.9 percent of total assets), followed by retirement savings accounts (superannuation, 19.9 percent), and other financial assets (13.6 percent). In older age groups, retirement savings accounts represent a much smaller share of total assets than in younger age groups, reflecting the fact that superannuation was only introduced in 1992 and thus older members of our sample did not contribute much to superannuation during their working lives. In addition, older members will have drawn on those accounts during retirement. In those age groups, other financial assets, mainly securities, are far more important.

Median total household debt in the sample as a whole is $\$ 12,000$, while median debt by age group declines from $\$ 134,000$ in the $40-44$ age group down to 0 in all age groups above 65. In younger households, debt is dominated by mortgages, whereas older households' debt is mainly comprised of other forms of debt. Median net worth is $\$ 604,164$.

There is a high degree of variability of income and wealth across the population. Looking at disposable income, the ratio of the 90th percentile to the 10th percentile is 7.0 when taking into account the entire sample. Across age groups, this ratio is largest in the 65-69 age group (7.0) and lowest in the 40-44 age group (4.0). Disparities are even greater for net worth. Here, the 
ratio of the 90th percentile to the 10th percentile is 51.0 for the entire sample, highest in the 75-79 age group (80.6) and lowest in the 55-59 age group (18.4).

In summary, there is a high degree of heterogeneity in income and wealth across our sample, as well as in the composition of income and wealth. Thus, we expect there to be a correspondingly high degree of heterogeneity in adequacy of retirement savings. More detailed descriptive statistics summarizing the socio-demographic, income, and wealth characteristics for our sample are presented in Tables A.1-A.3 (available in the Appendix, in the Online Supporting Information).

\section{Results}

We now combine the HILDA dataset with our algorithm to calculate the adequacy metrics described in Section 2 . In all of our analyses, we produce four alternative projections of the consumption level in retirement, with each successive projection taking into account one additional source ("pillar") of retirement income. The first projection considers only compulsory retirement savings (compulsory superannuation). In the second projection, we add voluntary superannuation contributions, while the third projection additionally takes into account the government pension (called the Age Pension in Australia). Finally, we add other (net) savings to the pool of assets in the fourth projection. The latter information in particular is typically not included in estimates of retirement savings due to unavailability of data. To compute net savings, we add bank account balances, cash investments, equity investments (net of investment loans), assets in trusts, life insurance contracts, property assets (excluding the home, net of mortgages on those properties), and business assets (net of business debt). The last projection, taking into account all pillars of retirement savings, provides our primary set of results, while differences between the outcomes of the alternative projections provide information on the relative contributions of the various pillars.

\subsection{Consumption Level and Consumption Shortfall}

4.1.1 Consumption Level 
Results are presented separately for singles and couples below and above the retirement age of 65 (Table 1 ).

Projected consumption levels are shown in Panel A of Table 1 and consumption shortfalls in Panel B. If we consider only compulsory retirement savings as a source of retirement income (projection 1), the situation appears grim. 18 In the 40-64 age group, the median consumption during retirement for singles, is less than one third of the relative poverty line in Australia (half of median equivalized disposable income in the population, and equal to $\$ 19,990$ in 2010).

Consequently, the estimated median projected consumption shortfall in the 40-64 age group, when only compulsory retirement savings are considered, is large. (It is $\$ 32,086$ for singles and $\$ 31,887$ for couples, or 83.7 percent and 60.8 percent of the ASFA comfortable standard, respectively). It is therefore clear that, for individuals in this age range, compulsory retirement savings are not yet nearly sufficient to fund a comfortable level of consumption during retirement Couples are, however, better placed than singles.

Taking into account voluntary contributions to retirement savings accounts (projection 2) does not change consumption levels or the consumption shortfall materially, reflecting the fact that most people do not make significant voluntary contributions.

Adding the government pension to the projection of consumption levels (projection 3) changes median consumption levels significantly, to $\$ 23,767$ and $\$ 44,995$ for singles and couples respectively, more than tripling the estimates for singles and more than doubling the estimates for couples compared to projection 2 . This reduces the median consumption shortfall, to $\$ 14,572$ for singles (38.0 percent below the target comfortable level) and $\$ 7,477$ for couples (14.2 percent below target).

Adding other sources of retirement income (projection 4) increases the estimated median consumption level to $\$ 25,946$ for singles and $\$ 52,500$ for couples, representing respective increases of 9.2 percent and 16.7 percent 
relative to the projections without these other sources. Consequently, the median shortfall is reduced further, to $\$ 12,393$ for singles (32.3 percent below target) and to just below zero (-\$28) for couples. While just over half of couples appear on track to achieve a comfortable level of retirement income, the shortfall for singles remains significant even when taking all sources of income into account. As Table 1 indicates, less than 25 percent of singles are on track to reach the target comfortable level. The contribution of other sources increases with percentiles in the distribution. At the $90^{\text {th }}$ percentile of consumption levels, for example, the difference between projections 3 and 4 is 34.7 percent for singles and 68.9 percent for couples.

This analysis shows that omitting sources of retirement savings other than retirement savings accounts can lead to severe underestimation of consumption levels in retirement. It also shows that the Age Pension makes a major contribution to achieving adequacy, but that non-superannuation savings are also important.

Looking at the individuals aged 65 and above, we find that the estimated median consumption level based on compulsory retirement savings alone is zero. This is unsurprising, since the youngest members of this age group were already aged 47 when compulsory contributions were introduced. As a consequence, their lifetime compulsory contributions would be relatively low and, for many in this age group, have already been exhausted by 2010 (when they were well into their retirement). Their consumption is thus mainly funded by the government pension and other retirement savings. In this group, the omission of other retirement savings has even greater effects on the estimation of consumption levels and consumption shortfalls. The difference between median consumption levels in projections 3 and 4 is 29.8 percent for singles and 39.6 percent for couples.

The median consumption shortfall in projection 3 (retirement savings and government pension) is $\$ 19,596$ (51.1 percent of target) for singles and $\$ 24,216$ (63.2 percent) for couples. Adding other savings to the projections reduces the median shortfall to $\$ 14,010$ (36.5 percent) for singles and 
$\$ 13,021$ (34.0 percent) for couples. It is worth noting that, while the consumption shortfall is significantly larger for singles than for couples in the 40-64 age group, this is not the case in the group aged 65 and older.

We also examined to what extent consumption levels and shortfalls in projection 4 varied by age group, as well as a set of measures indicating the level of dependency of retirees on the government pension (Table 2). For singles, the median consumption shortfall increases with age, peaking in the 65-69 age group. In the case of couples, there is no clear trend among the younger age groups, while the consumption shortfall peaks in the 75-79 age group.

Among those aged 40-64, the consumption shortfall is negative in 79.4 percent of cases for singles and 49.8 percent of cases for couples; 95.8 percent of singles are projected to receive at least a partial government pension, which on average over their retirement years contributes 61.3 percent of their income; in the case of couples, 88.8 percent are projected to receive the government pension, which on average contributes 39.1 percent to their income.

Comparing individuals aged 40-64 with individuals aged 65 and above, for singles there is little difference in the consumption shortfall and in reliance on the government pension. However, there are marked differences in the case of couples: the median consumption shortfall is $-\$ 28$ in the $40-64$ age group and $\$ 13,021$ in the 65 and older age group, while the mean contribution of the government pension to income is 39.5 percent in the 40-64 age group, compared to 60.5 per cent in the 65 and older age group. A likely explanation for this trend of decreasing reliance on the government pension is mandatory retirement savings. Those in the 65 and older age group only received contributions to superannuation for a small part of their working lives, while those in the 40-64 age group, and particularly the younger members of this age group, will contribute to superannuation for a significant part of their working lives. Further analysis is required, however, to establish the causes of this difference across age groups in dependency on the government pension. 
[PLACE TABLES 1 AND 2 NEAR HERE]

\subsection{Run-Out Age and Age Gap}

We now turn to the second set of adequacy metrics, run-out age and age gap, presented in Table 3.

\subsubsection{Run-Out Age}

In the 40-64 age group, the median run-out age is 69 years for singles in both projections 1 and 2 (compulsory and voluntary superannuation), while for couples it is 75 years in projection 1 and 76 years in projection 2 (Panel A of Table 3). In projection 3 (including the government pension), the median runout age does not change for singles in the 40-64 age group, but increases to 82 years for couples in the same age group because eligibility for the government pension enables conservation of private savings. Finally, in projection 4, the median run-out age is 71 years for singles in the 40-64 age group and 92 years for couples. In most of our projections, the run-out age is substantially below life expectancy, a point to which we now turn.

\subsubsection{Age Gap}

The age gap metric compares run-out age to life expectancy, given a member's current age. In projection 1 (compulsory retirement savings only), 50 percent of singles in the 40-64 age group are expected to run out of private retirement savings 20 years before life expectancy, compared to 13 years for couples (Panel B of Table 3). $\underline{19}$

The age gap does not narrow when adding voluntary superannuation contributions. Adding the government pension in projection 3 does not change the median age gap for singles, but reduces it from 13 years to 6 years in the case of couples. When adding other retirement savings in projection 4 , the median age gap decreases to 18 years for singles and to -4 years for couples.

Considering projection 4, which takes into account all pillars of savings, in the 40-64 age group, 77.2 percent of singles and 45.6 percent of couples are 
expected to run out of retirement savings before life expectancy, compared to 68.2 percent of singles and 62.8 of couples in the 65 and older age group. This means that even when taking into account all sources of retirement income, the majority of the population is unable to fund a comfortable level of consumption for the entire expected period of retirement.

\section{[PLACE TABLE 3 NEAR HERE]}

\subsection{Replacement Ratios}

The most widely used measure of adequacy of retirement savings is the income replacement ratio. It computes the ratio of expected income during retirement to pre-retirement disposable income. We estimated the income replacement ratio for the population aged $40-64$ in 2010, calculated as the ratio of the projected retirement consumption level to actual disposable income in 2010 (Table 4). Taking into account only compulsory retirement savings (projection 1) leads to a median income replacement ratio of 12.8 percent for singles and 32.9 percent for couples. Adding voluntary superannuation contributions and the government pension (projection 3) leads to a median replacement ratio of 54.5 percent for singles and 49.5 percent for couples. Finally, in projection 4, taking into account all sources of retirement income, the median income replacement ratio is 63.0 percent for singles and 59.1 percent for couples. It is noteworthy that in projections 3 and 4 , the income replacement ratio is higher for singles than for couples, yet the consumption shortfall is lower for couples than for singles. This points to the significance of the retirement income target that is being adopted when measuring adequacy, which we will discuss later in this section.

\section{[PLACE TABLE 4 NEAR HERE]}

\subsection{Heterogeneity of Retirement Savings Adequacy}

There is, of course, considerable heterogeneity in income and wealth across individuals, which we expect to be reflected in the measures of retirement savings adequacy. To this extent, we computed medians of the different adequacy metrics by socio-demographic characteristics separately for the $40-$ 
64 age group (Table A.4) and the 65 and above age group (Table A.5). We will focus our discussion on the former.

Retirement savings adequacy is substantially worse for women than for men across all five metrics presented. Adequacy increases with income when considering consumption and age metrics, but decreases when considering the income replacement ratio. That is, while consumption levels increase with income, the income replacement ratio decreases. This relation is due to the fact that individuals with lower current income levels will be able to achieve a higher replacement ratio than individuals with higher current income levels. The main reason for this phenomenon is the government pension, which will replace a much larger part of current income for low-income individuals. Thus, many low-income people with a high projected income replacement ratio will nonetheless have low living standards in retirement, while many high-income people with a low projected income replacement ratio will nonetheless have relatively high living standards in retirement.

In our sample, retirement savings adequacy improves with net worth (Table A.4). It is slightly higher for couples with dependent children than for couples without children. This difference is likely driven by higher income and wealth in the former group. Adequacy is lower for lone parents than for lone persons. Adequacy increases with the number of children until two and then decreases, and is lowest for households with four or more children. Adequacy also increases with educational attainment and decreases with remoteness of residence. It is substantially lower for the non-employed than the employed, and significantly lower for individuals who have already retired than for those who have not yet retired.

Next, we examine heterogeneity of savings adequacy across sociodemographic groups from an alternative perspective. We distinguish individuals by degree of dependency of retirement income on the government pension: 100 percent dependence; less than 100 percent but at least 50 percent dependence (50-100 percent); less than 50 percent but greater than 0 percent dependence (0-50 percent); and 0 percent dependence. As before, 
we see a shift in dependency with age group. In the 40-64 age group, most people fall into the 0-50 percent dependency category (Table A.6), while in the 65 and older age group, most people fall into the 50-100 percent dependency category (Table A.7).

Looking at the 40-64 age group, the group that is exclusively dependent on the government pension (100 percent dependency) is dominated by females (64.6 percent), while in the other dependency categories, the male/female ratio is around 1. Individuals with higher dependency on the government pension tend to be slightly older and have low current levels of income. Indeed, 79.7 percent of individuals in this group are in the bottom quartile of current household disposable income, while in the group with no dependency on the government pension, only 6.5 percent are located in this income quartile.

Looking at current net worth levels, median net worth in the group with the highest dependency levels (100 percent) is $\$ 10,335$, compared to $\$ 2,956,800$ in the lowest-dependency group (0 percent). The majority of people in the highest-dependency group are lone parents and lone persons, whereas in the lower-dependency groups the majority are couples. In the highestdependency group, the majority of people did not complete high school and only 8 percent have university degrees, whereas in the lowest-dependency group 45.7 percent have university degrees and only 17.6 percent did not complete high school. In the highest-dependency group, 91.1 percent are unemployed and 48.9 percent are retired, whereas in the lowest-dependency group only 18 percent are not employed and 9.6 percent are retired.

\subsection{The Relation Between Adequacy Metrics and Other Financial Indicators}

We now consider the relation between the different adequacy metrics across the four projections, as well as the relationship between these metrics and key indicators of financial well-being, using Spearman rank correlations, with the aim to see to what extent key financial indicators proxy for adequacy (Table 5). All correlations reported are significant at the $p<0.001$ level. 
We first look at correlations of the same adequacy metric across the four projections considered above. Table 5 shows that correlations of the consumption shortfall metrics across the first three projections are all above 0.9 , indicating that the metric in those three projections conveys about the same amount of information. However, the correlation between the consumption shortfall in the first three projections and the consumption shortfall in projection four is significantly lower. For example, it is 0.7256 between projections 3 and 4 . This lower correlation indicates that the addition of other assets to the estimation of retirement saving adequacy adds a significant amount of information, as indicated by earlier analyses. The correlations in the age gap metric across the four projections exhibit a similar pattern and therefore lead to a similar conclusion.

To compare the ordering of individuals across the two metrics, we examined the correlation between the projection 4 consumption shortfall metric and the projection 4 age gap metric. This was found to equal 0.971 , implying that the two metrics provide very similar predictions, and suggesting that the choice between them for provision of information to individuals about retirement savings adequacy is likely to depend on behavioral considerations.

\section{[PLACE TABLE 5 NEAR HERE]}

The consumption shortfall and age gap are also moderately correlated with household disposable income, superannuation balance, and net worth (Table 5).

Next, we regressed the consumption shortfall in projection 4 on those key financial indicators as well as a set of socio-demographic characteristics (Table A.8). These results indicate that each of those indicators is correlated with consumption shortfall, even when controling for socio-demographic characteristics. The best predictor is net worth (Table A.8, models 5 and 6). When considering those three key financial variables together (Table A.8, models 7 and 8), only the coefficients of disposable income and net worth are significant, even when controling for socio-demographic factors. This 
suggests that the current superannuation balance provides no information additional to that provided by the other two financial variables when predicting the consumption shortfall.

Finally, we report correlations between the four adequacy metrics (projection 4) and the income replacement ratio (Table 6, bottom row). Particularly relevant for our argument that the replacement ratio may not be particularly informative for indicating retirement savings adequacy, the correlation between consumption level and income replacement ratio is 0.1404. Correlations with the income replacement ratio are slightly higher for the other three adequacy metrics, but none is higher than 0.22 .

\section{[PLACE TABLE 6 NEAR HERE]}

\section{Discussion}

In this paper, we propose four metrics to measure the adequacy of retirement savings, two based on consumption levels during retirement and two based on the expected age of running out of retirement savings. We then estimate these metrics for a representative sample of the Australian population aged 40 and above using data from the HILDA Survey, producing alternative projections which successively build in each of the four pillars of the Australian retirement income system.

We find that omitting one or more of the pillars of retirement savings leads to significant underestimation of projected consumption levels during retirement. One "pillar" of retirement savings that is often not taken into account when projecting retirement income is savings vehicles other than dedicated retirement savings accounts (e.g. $401(\mathrm{k})$ accounts in the U.S. and superannuation accounts in Australia). We show that omission of this voluntary savings pillar can lead to underestimation of projected consumption levels in retirement of 40 percent or more, and that underestimation is particularly pronounced among people with high expected levels of consumption. We conclude from this part of the analysis that assessment of the adequacy of retirement savings should take into account all sources of 
retirement income, and not just dedicated retirement savings accounts and social security payments, as is often the case.

As our analyses make clear, the introduction of compulsory retirement savings in Australia seems to have reduced the relative contribution of the government pension to retirement income while increasing the contribution of (largely defined-contribution) retirement savings accounts. This means that the proportion of consumption from potentially risky assets, in particular those in retirement savings accounts, is increasing. This has implications for optimal portfolio allocation and suggests that portfolio allocation too needs to take into account all sources of retirement income, in particular government pensions, property, and other assets, rather than focusing in isolation on (a particular set of) retirement savings accounts such as $401(\mathrm{k})$ accounts in the U.S. or their equivalents elsewhere (Wood, 2013). At the same time, it also suggests that it is important to take risk into account when projecting adequacy of retirement savings, which is the subject of ongoing and planned future work by the authors.

We also report large heterogeneity in the adequacy of retirement savings across the population. This finding suggests that a "one-size-fits-all" policy approach to promoting retirement savings is likely to be inappropriate, and that more personalized approaches should be pursued, taking individual circumstances into account.

A further key finding is the high correlations between our adequacy metrics, which suggests that any of them could potentially be used in providing financial advice and guidance on retirement savings adequacy. Further research identifying which has more resonance with individuals and effect on behavior is thus warranted. Also important are the low correlations between our metrics and the income replacement ratio, calling into question the merit of relying on the latter in financial advice provision. Most importantly, the income replacement ratio tends to be higher for low-income groups and lower for high-income groups, while projected consumption levels in retirement are higher for the latter group than for the former. We conclude that the 
assessment of savings adequacy should at least be supplemented by the kind of metrics we propose.

We also find that commonly used indicators of financial well-being such as current household income, superannuation balance, and net worth are not necessarily good "proxies" for measures of adequacy of retirement savings. In other words, the position of individuals in the distributions of current household income, superannuation balance, and net worth are not necessarily good reflections of their positions in the distribution of eventual retirement savings adequacy.

The projection of consumption levels during retirement of course depends on a large set of assumptions about individual, household, and market factors, including wages, salaries, and other income across the life cycle, real wage growth, employment status, marital status, home-ownership status, and retirement age, as well as asset returns and their temporal patterns. We keep all of the factors constant in the projections presented in this paper to focus on the presentation of a new set of adequacy metrics and the assessment of the relative contributions of the four pillars of retirement savings. An important direction of research in this area is the introduction into the model of uncertainty about the factors influencing adequacy, particularly stochastic asset returns and the impact of planned or involuntary retirement at different ages, and the investigation of the sensitivity of adequacy metrics to changes in the factors influencing retirement adequacy.

Finally, we also report significant gaps between the level of income individuals expect to need during retirement for a satisfactory lifestyle and their projected income in retirement. While the HILDA Survey data does not contain information about individuals' own assessments of the adequacy of their current retirement savings, other studies report that a large fraction of the population acknowledge that they are not saving enough and would like to save more (Carroll et al., 2009). Our metrics can provide indications of the level of consumption that people can expect in retirement, given their current financial circumstances. Thus, our metrics can assist people in the 
development of optimal consumption-savings strategies, possibly in combination with other metrics such as the income replacement ratio.

We believe that one means to help close the retirement savings gap is the provision of easily accessible tools, such as online retirement savings calculators or "financial health checks," that help people assess the adequacy of their own retirement savings using metrics like the ones we present in this paper. Information provision of this sort is potentially one important addition to other measures to promote retirement savings, such as tax incentives, reducing pension eligibility (e.g. by increasing the minimum age of eligibility), and the promotion of appropriate investment strategies. However, the efficacy of various mechanisms such as these is an unresolved empirical question, and warrants further investigation.

\section{References}

ASFA (Association of Superannuation Funds of Australia), ASFA Retirement Standards, ASFA, Sydney, 2012.

Australian Centre for Financial Studies and Mercer, Melbourne Mercer Global Pension Index, Melbourne, 2016.

Basu, A. and M. Drew, "The Appropriateness of Default Investment Options in Defined Contribution Plans: Australian Evidence," Pacific Basin Financial J ournal, 18(3), 290-305, 2010.

Benarti, S., Save More Tomorrow: Practical Behavioral Finance Solutions to Improve 401(k), Penguin, New York, 2012.

Bernheim, B. D., Is the Baby Boom Generation Preparing Adequately for Retirement? Merrill Lynch, New York, 1992.

and A. Rangel, "Behavioral Public Economics: Welfare and

Policy Analysis with Non-standard Decision-Makers," National Bureau of Economic Research, Washington, DC, 2005. 
, J S Skinner, and S. Weinberg, "What Accounts for the

Variation in Retirement Wealth among US Households?" American Economic Review, 91(4), 832-57, 2001.

Beshears, J ., J . J . Choi, D. Laibson, and B. C. Madrian, "The Importance of Default Options for Retirement Savings Outcomes: Evidence from the United States," in J . Brown (ed.), Social Security Policy in a Changing World, University of Chicago Press, Chicago, 2009.

Booth, P. and Y. Yakoubov, "Investment Policy for Defined-Contribution Pension Scheme Members Close to Retirement: An Analysis of the "Lifestyle" Concept," North American Actuarial J ournal, 4, 1-19, 2000.

Browning, M. and T. J . Crossley, "The Life-Cycle Model of Consumption and Saving,"The J ournal of Economic Perspectives, 15(3), 3-22, 2001.

Carroll, G. D., J . J . Choi, D. Laibson, B. C. Madrian, and A. Metrick, "Optimal Defaults and Active Decisions," Quarterly J ournal of Economics, 124(4), 1639-74, 2009.

Choi, J . J ., D. Laibson, and B. C. Madrian, "Plan Design and 401(k) Savings Outcomes," National Tax J ournal, 57(2), 275-98, 2004.

Haisken-DeNew, J . P. and M. H. Hahn, "PanelWhiz: Efficient Data Extraction of Complex Panel Data Sets-An Example Using the German SOEP," Schmollers J ahrbuch, 130(4), 643-54, 2010.

IMF (International Monetary Fund), The Quest for Lasting Stability, Global Financial Stability Report, IMF, Washington, DC, 2012.

Lusardi, A. and O. S. Mitchell, "Baby Boomer Retirement Security: The Roles of Planning, Financial Literacy, and Housing Wealth,"J ournal of Monetary Economics, 54(1), 205-24, 2007. 
Munnell, A. H., F. Golub-Sass, and A. Webb, "How Much To Save For A Secure Retirement," Issue in Brief, Center for Retirement Research, Boston College, Chestnut Hill, MA, 2011.

, A. Webb, and L. Delorme, "Retirements at Risk: A New National Retirement Index," Boston College Center for Retirement Research, Chestnut Hill, MA, 2006.

OECD (Organization for Economic Cooperation and Development), Growing Unequal? Income Distribution and Poverty in OECD Countries, OECD, Paris, 2008.

Purcell, P. J ., "Income Replacement Ratios in the Health and Retirement Study," Social Security Bulletin, 72(3), 37-58, 2012.

Reyna, V. F. and C. J . Brainerd, "The Importance of Mathematics in Health and Human J udgment: Numeracy, Risk Communication, and Medical Decision Making," Learning and Individual Differences, 17(2), 147-59, 2007.

Skinner, J ., "Are You Sure You're Saving Enough for Retirement?"J oumal of Economic Perspectives, 21(3), 59-80, 2007.

Summerfield, M., S. Freidin, M. Hahn, N. Li, N. Macalalad, L. Mundy, N. Watson, R. Wilkins, and M. Wooden, HILDA User Manual-Release 11, Melbourne Institute of Applied Economic and Social Research, The University of Melbourne, 2012.

Watson, N., 'Longitudinal and Cross-Sectional Weighting Methodology for the HILDA Survey," HILDA ProjectTechnical Paper Series No. 2/12, Melbourne Institute of Applied Economic and Social Research, The University of Melbourne, Melboume, 2012.

Wood, J ., "Examining the Equity Holdings of Australian Superannuation Funds,"J ASSA-The Finsia J ournal of Applied Finance, 2, 7-11, 2013. 
Wooden, M. and N. Watson, "The HILDA Survey and its Contribution to Economic and Social Research (So Far),"Economic Record, 83 (261), 20831, 2007.

World Bank, The World Bank Pension Conceptual Framework, World Bank, Washington, DC, 2008.

\section{Notes}

1 Strictly speaking, the terminology should refer to a cash flow, because some part of the post-retirement funds received and used for consumption is a running down of the capital amount available. For ease of exposition, we use the term "income" to refer to the cash flow stream and also to consumption, and only distinguish between post-retirement income and consumption when that is required by the analysis.

2Since, in both cases, the latter metric is essentially a linear transformation of the former, discussion of each would lead to unnecessary duplication.

3. Our focus here relates to practices which are, or can be, applied in financial advice or policy discussion rather than theoretical approaches such as use of life-cycle models.

4 Strictly speaking, the terminology should refer to a cash flow, because some part of the post-retirement funds received and used for consumption is a running down of the capital amount available.

5EConomic theory, based on rational optimizing behavior, leads naturally to a life-cycle perspective on individual consumption-savings choices in which consumption (utility) would be smoothed over the life cycle. In this stylistic framework, a replacement ratio approach to adequacy of retirement savings has merit, with replacement ratios of less than unity reflecting lower income needs and consumption preferences in retirement to maintain a constant level of utility. However, the variety of life-cycle models found in the literature with varying behavioral or institutional assumptions needed to fit the data suggest 
that it is necessary to go beyond the replacement ratio approach-particularly for individuals some distance away from retirement (Browning and Crossley, 2001).

6 More specifically, we use the so-called "comfortable" levels provided by ASFA in December 2012 and deflate them to 2010 dollars to align to the HILDA data timing. In this paper, all dollar figures are expressed in Australian dollars at 2010 prices, unless stated otherwise.

IWe accept that consumption-savings choices during the working life, based on a life-cycle or other model of behavior, would not involve a retirement target of the ASFA comfortable standard for many (most) lower-income groups. That level of consumption is not in their feasible set, even during their working life, given their lifetime income levels. But we reiterate that our approach is as much about social policy concerns as it is about economic theories of behavior-specifically, about how far from an "adequate" level of retirement income current savings pattems will lead. By providing information at stages during the working life, our metrics can enable those able to adjust their behavior to do so, and for governments to realize the policy challenges involved in the cases of those for whom the comfortable level is infeasible.

8As we cannot separate the value of past voluntary contributions from the past compulsory contributions included in the retirement savings account balance, our Pillars 2 and 3 should be viewed in combination. Our Pillar 2 includes actual past voluntary contributions, while our Pillar 3 includes expected future voluntary contributions.

9The eligibility age has been increasing since 1996 for women, from 60 prior to 1996 up to 65 as of J anuary 1, 2014. The pension eligibility age is scheduled to increase in steps up to age 67 by J uly 1, 2023 .

10 Since then, legislation has been changed to achieve the 12 percent level of contributions by J uly 1, 2025 . 
11.The zero tax treatment of superannuation earnings in the retirement phase means that a higher after-tax rate of return is assumed for that period.

12 Annual steps are used, with additions to wealth (or subtractions in the retirement phase) assumed to occur mid-year, apart from govemment cocontributions, which are applied at the end of the year. Our calculations are based on an extension of an algorithm that was initially developed by Willis Towers Watson for the Australian Securities and Investment Commission MoneySmart calculator. The calculator enables individuals to input personal financial details and obtain output on likely shortfalls in retirement consumption in the form discussed above. The calculator is publicly available at http://www.moneysmart.gov.au.

13 The data used in this paper were extracted using the Add-On package PanelWhiz v4.0 (October 2012) for Stata. PanelWhiz was written by Dr. J ohn P. Haisken-DeNew (john@panelwhiz.eu). The PanelWhiz-generated DO file to retrieve the HILDA data used here and any Panelwhiz Plugins are available upon request. Any data or computational errors in this paper are our own. Haisken-DeNew and Hahn (2010) describe PanelWhiz in detail.

14More information about the Australian retirement income system and comparisons with systems in other major countries can be found in the documentation describing the Melboume Mercer Global Pension Index available at http://www. globalpensionindex.com (Australian Centre for Financial Studies and Mercer, 2016).

15 The higher after tax retum after retirement reflects the zero tax rate applied to superannuation fund eamings in that phase.

16 This is also relevant for calculating pension amounts given the linking of the full pension to 25 percent of average weekly earnings.

17 Income is equivalized using the modified OECD scale, whereby household income is divided by the equivalence scale. The scale is equal to one plus 0.5 
for each additional household member after the first aged 15 and over plus 0.3 for each child aged under 15 .

18 We start with superannuation retirement savings rather than the Age Pension because some policy discussion in Australia involves assuming that the compulsory superannuation system will eventually replace rather than supplement the Age Pension.

19 The age gap for couples is computed by considering the life expectancy of the male partner.

Supporting Information

Appendix

Table A.1: Sample Summary Statistics

Table A.2: Sample Statistics of Income and Wealth Structure

Table A.3: Sample Statistics of Income and Wealth Distribution

Table A.4: Medians of Adequacy Metrics by Demographic Characteristic (Persons Aged 40-64)

Table A.5: Medians of Adequacy Metrics By Demographic Characteristic (Persons Aged 65+)

Table A.6: Dependency on Government Pension in Retirement by Demographic Characteristic (Persons Aged 40-64)

Table A.7: Dependency on Government Pension in Retirement by Demographic Characteristic (Persons Aged 65+)

Table A.8: Regression Results

Fig. 1 Pillars of Retirement Income 
Notes: The four pillars of the Australian retirement savings system largely correspond to the five pillars of the World Bank's "Five Pillar Framework" of retirement savings (World Bank, 2008).

Fig. 2 Adequacy Metrics

Notes: This figure shows the relations between our four adequacy metrics.

Table 1 Summary Statistics of Consumption Level and Consumption Shortfall Metrics (\$)

p10 p25 Median p75 p90 Mean SD

Panel A. Consumption level

Al/ people aged 40-64

\section{Singles}

Super onlya

$\begin{array}{llllll}0 & 744 & 6,253 & 14,04825,985 & 10,468 & 14,273\end{array}$

Super onlyb

$\begin{array}{llllll}0 & 744 & 6,428 & 14,53927,470 & 10,829 & 14,739\end{array}$

Superb + Age Pension

17,301 18,743 23,767 30,553 38,693 26,695 11,557

Super + Age Pension + other assets 17,768 19,668 25,946 35,722 52,132 33,347 28,336

\section{Couples}

Super onlya

Super onlyb

Superb + Age Pension
$857 \quad 8,322 \quad 20,585 \quad 37,28160,151 \quad 27,24028,228$ $857 \quad 8,452 \quad 20,875 \quad 38,27761,953 \quad 27,87528,703$ 28,051 34,352 44,995 56,138 71,809 48,397 22,706

\section{All people aged 65 and above}

\section{Singles}

Super onlya

Super only

Superb +Age Pension

Super $^{\text {+ }}$ Age Pension + other assets 18,744 19,344 24,329 35,231 59,153 37,518 48,154

\section{Couples}

$\begin{array}{lllllll}0 & 0 & 0 & 0 & 6,976 & 2,441 & 10,183 \\ 0 & 0 & 0 & 0 & 6,976 & 2,441 & 10,183\end{array}$

$18,74318,743$ 18,743 18,743 25,970 20,897 8,804 
p10 p25 Median p75 p90 Mean SD

Super onlya

$\begin{array}{lllll}0 & 0 & 0 & 10,59535,858 & 11,91929,202\end{array}$

Super onlyb

$\begin{array}{lllll}0 & 0 & 0 & 10,59535,858 & 11,91929,202\end{array}$

Super + Age Pension

$28,25628,25628,25638,57657,475 \quad 37,91724,781$

Superb + Age Pension + other assets 28,376 30,054 39,451 62,374 116,804 64,208 76,056

Panel B. Consumption shortfall

\section{All people aged 40-64}

Singles

Super onlya

38,339 37,595 32,086 24,291-12,354 27,871 14,273

Super onlyb

$38,33937,59531,91123,800-10,86927,51014,739$

Superb +Age Pension

$21,03819,59614,572-7,786354$

$11,64411,557$

Superb + Age Pension + other assets 20,571 18,671 12,393-2,617 13,793 -4,992 28,336

\section{Couples}

Super onlya

$51,61544,15031,887 \quad 15,1917,679 \quad 25,23228,228$

Super only

$51,61544,02031,597 \quad 14,1959,481 \quad 24,59728,703$

Super + Age Pension

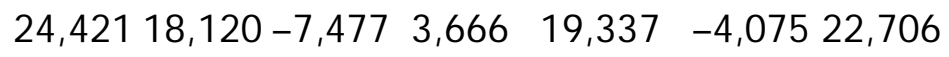

Superb + Age Pension + other assets 23,015 12,230 28

$21,25668,852 \quad 20,35475,210$

\section{All people aged 65 and above}

\section{Singles}

Super onlya

38,339 38,339 38,339 38,339-31,363 35,898 10,183

Super onlyb

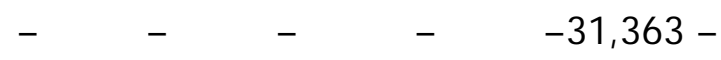

10,183 


$\begin{array}{cccccc}\text { p10 } & \text { p25 } & \text { Median p75 } & \text { p90 } & \text { Mean } & \text { SD } \\ 38,339 & 38,339 & 38,339 & 38,339 & 35,898 & \end{array}$

Super + Age Pension

$19,59619,59619,59619,596-12,36917,4428,804$

\section{Superb +
Couples}

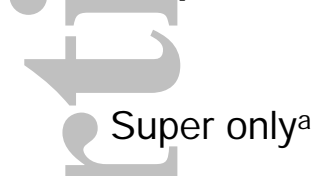

Super onlyb

Super + Age Pension
$52,47252,47252,47241,877-16,614$ 40,553 29,202

$52,47252,47252,47241,877-16,61440,55329,202$

$24,21624,21624,21613,8965,003 \quad 14,55524,781$

Super + Age Pension + other assets 24,096 22,418 13,021 9,902 64,332 11,736 76,056

Notes: a Mandatory contributions only.

b Mandatory + voluntary contributions.

p10, 10th percentile; p25, 25th percentile; $p 75$, 75th percentile; $p 90,90$ th percentile; SD, standard deviation.

Source: The Household, Income, and Labour Dynamics in Australia Survey Wooden and Watson, 2007; own computations.

Table 2 Retirement Savings Adequacy and Dependency on Government Pension in Retirement by Age Group

$$
\begin{array}{llllllllll}
40-64 & >5 & 40-44 & 45-49 & 50-54 & 55-59 & 60-64 & 65-69 & 70-74 & 7
\end{array}
$$

\section{Singles}

Median consumption level (\$) 25,946 24,329 27,658 27,076 25,132 24,539 23,793 21,658 22,082 2 
$\begin{array}{lllllllll}40-64 & \succ 5 & 40-44 & 45-49 & 50-54 & 55-59 & 60-64 & 65-69 & 70-74\end{array}$

Median shortfall (\$)

$\%$ with negative shortfall

$\%$ receiving Age Pension

$\%$ contribution of Age Pension 61.3
$12,39314,010$

$79.4 \quad 77.9$

$95.8 \quad 96.9$

68.4
10,68 $79.3 \quad 74.8$

95.496 .1 $57.3 \quad 58$
11,263

4.8

.1

\section{Couples}

Median consumption level (\$) 52,500 39,451 52,998 53,752 53,879 52,499 47,368 43,634 37,065 3

Median shortfall (\$)

$\%$ with negative shortfall

$\%$ receiving Age Pension

$\%$ contribution of Age Pension $39.1 \quad 60.5$
$28 \quad 13,021526$

$49.8 \quad 67$

48.2

89.1 $35.7 \quad 36.6 \quad 38$
$1,280 \quad 1,407 \quad 27$

47.5

47.3

89.3

49.9

87.2

40.1
$-5,104-8,83815,4071$

$58.1 \quad 65.1$

$88.2 \quad 91.2 \quad 94.3$

$47.1 \quad 56.5 \quad 61.9$ $(\mathrm{cos})$

Source: The Household, Income, and Labour Dynamics in Australia Survey Wooden and Watson, 2007; own computations.

Table 3 Summary Statistics of Run-Out Age and Age Gap Metrics p10 p25 Median p75 p90 Mean SD

\section{Panel A. Run-out age (years)}

All people aged 40-64

\section{Singles}

Super onlya $\begin{array}{lllllll}66 & 66 & 69 & 73 & 81 & 72 & 8\end{array}$

Super onlyb $\begin{array}{lllllll}66 & 66 & 69 & 73 & 82 & 72 & 8\end{array}$

Super ${ }^{b}+$ Age Pension $66 \quad 66 \quad 69$ $\begin{array}{llll}77 & 92 & 74 & 11\end{array}$

Superb + Age Pension + other assets $66 \quad 67 \quad 71$ $87 \quad 10678 \quad 15$

\section{Couples}

Super onlya

$\begin{array}{lllllll}67 & 70 & 75 & 83 & 97 & 78 & 11\end{array}$ 
p10 p25 Median p75 p90 Mean SD

Super onlyb

$\begin{array}{lllllll}67 & 70 & 76 & 84 & 98 & 79 & 11\end{array}$

Super + Age Pension

$\begin{array}{llllll}67 & 71 & 82 & 96 & 10684 & 15\end{array}$

Superb +Age Pension + other assets $69 \quad 77 \quad 92 \quad 10711492 \quad 16$

\section{All people aged 65 and above}

\section{Singles}

Super onlya

$\begin{array}{lllllll}69 & 73 & 79 & 86 & 90 & 80 & 8\end{array}$

Super onlyb

$\begin{array}{lllllll}69 & 73 & 79 & 86 & 90 & 80 & 8\end{array}$

Superb + Age Pension

$\begin{array}{lllllll}69 & 73 & 80 & 86 & 90 & 80 & 8\end{array}$

$\begin{array}{llllll}\text { Super }^{b}+\text { Age Pension + other assets } 70 & 75 & 84 & 93 & 10585 & 12\end{array}$

\section{Couples}

Super onlya

$\begin{array}{lllllll}69 & 72 & 76 & 81 & 88 & 78 & 9\end{array}$

Super onlyb

$\begin{array}{lllllll}69 & 72 & 76 & 81 & 88 & 78 & 9\end{array}$

Superb + Age Pension

$\begin{array}{lllllll}70 & 73 & 77 & 83 & 97 & 80 & 11\end{array}$

Super + Age Pension + other assets $\begin{array}{lllll}71 & 75 & 83 & 10011288 & 15\end{array}$

\section{Panel B. Age gap (years)}

\section{All people aged 40-64}

\section{Singles}

Süper onlya

$$
\begin{array}{lllll}
-24-23-20 & -16-7 & -17 & 8
\end{array}
$$

Super onlyb

$\begin{array}{llll}-24-23-20 & -15-6 & -17 & 9\end{array}$

Superb + Age Pension

$-24-23-20 \quad-125 \quad-15 \quad 11$

Superb + Age Pension +other assets -24 -22 -18 $\quad \begin{array}{lllll}-2 & 17 & -10 & 15\end{array}$

\section{Couples}

Super onlya

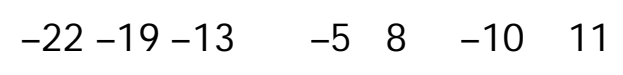

Super onlyb

$\begin{array}{lllll}-22-19-13 & -4 & 9 & -10 & 12\end{array}$

Superb + Age Pension

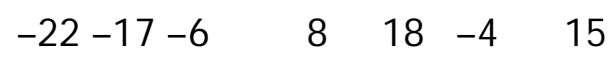

Super + Age Pension +other assets $-20-114$

$\begin{array}{llll}19 & 25 & 3 & 16\end{array}$

\section{All people aged 65 and above}

\section{Singles}




$$
\text { p10 p25 Median p75 p90 Mean SD }
$$

Super onlya

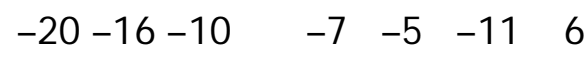

Super only $-20-16-10 \quad-7 \quad-5 \quad-11 \quad 6$

Super + Age Pension $\begin{array}{lllll}-19-16-10 & -6 & -4 & -11 & 7\end{array}$

Super $^{b}+$ Age Pension +other assets - $18-14-7 \quad \begin{array}{lllll}-1 & 13 & -6 & 11\end{array}$

\section{Couples}

Super onlya

Super onlyb

Super + Age Pension

Super ${ }^{b}+$ Age Pension + other assets $-17-13-7$

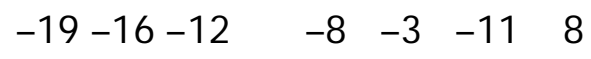

$\begin{array}{lllll}-19-16-12 & -8 & -3 & -11 & 8\end{array}$

$\begin{array}{lllll}-19-16-11 & -7 & 8 & -9 & 11\end{array}$

$\begin{array}{llll}12 & 23 & -1 & 15\end{array}$

Notes: a Mandatory contributions only.

b Mandatory + voluntary contributions.

p10, 10th percentile; p25, 25th percentile; $p 75$, 75th percentile; p90, 90th percentile; SD, standard deviation.

Source: The Household, Income, and Labour Dynamics in Australia Survey (Wooden and Watson, 2007); own computations.

Table 4 Summary Statistics of Replacement Ratio Metric

p10 p25 Median p75 p90 Mean

\section{Income replacement ratio (\%)}

Persons aged 40-64

Singles

$\begin{array}{lccclll}\text { Super onlya } & 0 & 2 & 12.8 & 25.444 .4 & 31.5 \\ \text { Super only }^{b} & 0 & 2 & 13.1 & 26.246 .2 & 32 \\ \text { Super } & \text { +Age Pension } & 27.738 .954 .5 & 81 & 115.3 & 154.9 \\ \text { Super }^{b}+\text { Age Pension +other assets } & 30.743 .963 & 94.6138 & 188\end{array}$


p10 p25 Median p75 p90 Mean

\section{Couples}

Super onlya

$\begin{array}{lllll}1 & 9.7 & 20 & 32.951 .8 & 27.7\end{array}$

Super onlyb

$\begin{array}{lllll}1 & 9.8 & 20.5 & 33.853 & 28.3\end{array}$

Superb + Age Pension

$26.335 .948 .5 \quad 65.391 .263 .1$

Super + Age Pension +other assets 31.943.2 59.1 87.2 129.7 90.3

Notes: a Mandatory contributions only.

b Mandatory + voluntary contributions.

$p 10,10$ th percentile; $p 25,25$ th percentile; $p 75$, 75th percentile; $p 90,90$ th percentile.

Source: The Household, Income, and Labour Dynamics in Australia Survey (Wooden and Watson, 2007); own computations.

Table 5 Correlations of Adequacy Metrics with Key Financial Indicators

Panel A. Correlations of consumption shortfall (CS) metrics and key financial indicators Net CS 1 CS 2 CS $3 \quad$ CS 4 Income Super worth
CS 1
1.0000

CS 2

0.9986* 1.0000

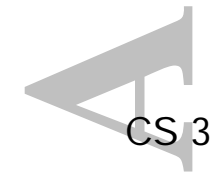

(0.0000)

$\operatorname{CS} 3$

$0.9439 * \quad 0.9455 * 1.0000$

(0.0000) (0.0000)

CS 4

0.6642* $0.6653^{*}$

$0.7256^{*}$

1.0000

$(0.0000)$

(0.0000)

$(0.00000)$

Income

$0.5222 *$

$0.5267 *$

0.6073*

0.5549* 1.0000 
Panel A. Correlations of consumption shortfall (CS) metrics and key financial indicators

$$
\begin{array}{llll}
(0.0000) & (0.0000) & (0.0000) & (0.0000)
\end{array}
$$

Super $\quad 0.7674 * 0.7687 * 0.8419 * \quad 0.6622 * \quad 0.6351 * 1.0000$

$$
\begin{array}{lllll}
(0.0000) & (0.0000) & (0.0000) & (0.0000) & (0.0000
\end{array}
$$

$\begin{array}{lllllll}\text { Net worth } & 0.3763^{*} & 0.3768 * & 0.4589 * & 0.7431 * & 0.4577 * & 0.6103 * \\ 1.0000\end{array}$

$\begin{array}{llllll}(0.0000) & (0.0000) & (0.0000) & (0.0000) & (0.0000) & (0.0000)\end{array}$

\begin{tabular}{|c|c|c|c|c|c|c|c|}
\hline & AP 1 & AP 2 & AP 3 & AP 4 & Income & Super & $\begin{array}{l}\text { Net } \\
\text { worth }\end{array}$ \\
\hline & 1.0000 & & & & & & \\
\hline 2 & 0.9978* & 1.0000 & & & & & \\
\hline & $(0.0000)$ & & & & & & \\
\hline & 0.9594* & $0.9644 *$ & 1.0000 & & & & \\
\hline & $(0.0000)$ & $(0.0000)$ & & & & & \\
\hline & 0.7313* & $0.7348 *$ & 0.7753* & 1.0000 & & & \\
\hline & $(0.0000)$ & $(0.0000)$ & $(0.0000)$ & & & & \\
\hline me & $0.3852 *$ & $0.3936 *$ & $0.5141^{*}$ & $0.5323 *$ & 1.0000 & & \\
\hline & $(0.0000)$ & $(0.0000)$ & $(0.0000)$ & $(0.0000)$ & & & \\
\hline & $0.5447 *$ & $0.5520 *$ & $0.6942 *$ & $0.6313^{*}$ & $0.6351^{*}$ & 1.0000 & \\
\hline & $(0.0000)$ & $(0.0000)$ & $(0.0000)$ & $(0.0000)$ & $(0.0000)$ & & \\
\hline Net worth & $0.4313^{*}$ & $0.4330^{*}$ & $0.4901^{*}$ & $0.7522 *$ & $0.4576 *$ & $0.6108^{*}$ & 1.0000 \\
\hline & $(0.0000)$ & $(0.0000)$ & $(0.0000)$ & $(0.0000)$ & $(0.0000)$ & $(0.0000)$ & \\
\hline
\end{tabular}

Panel B. Comelations of age gap (AP) metrics and key financial indicators

Notes: p-values in parentheses. Income, household disposable income;

Super, household superannuation balance; Net worth, household net worth. 
Source: The Household, Income, and Labour Dynamics in Australia Survey (Wooden and Watson, 2007); own computations.

Table 6 Pair-Wise Correlations of Adequacy Metrics

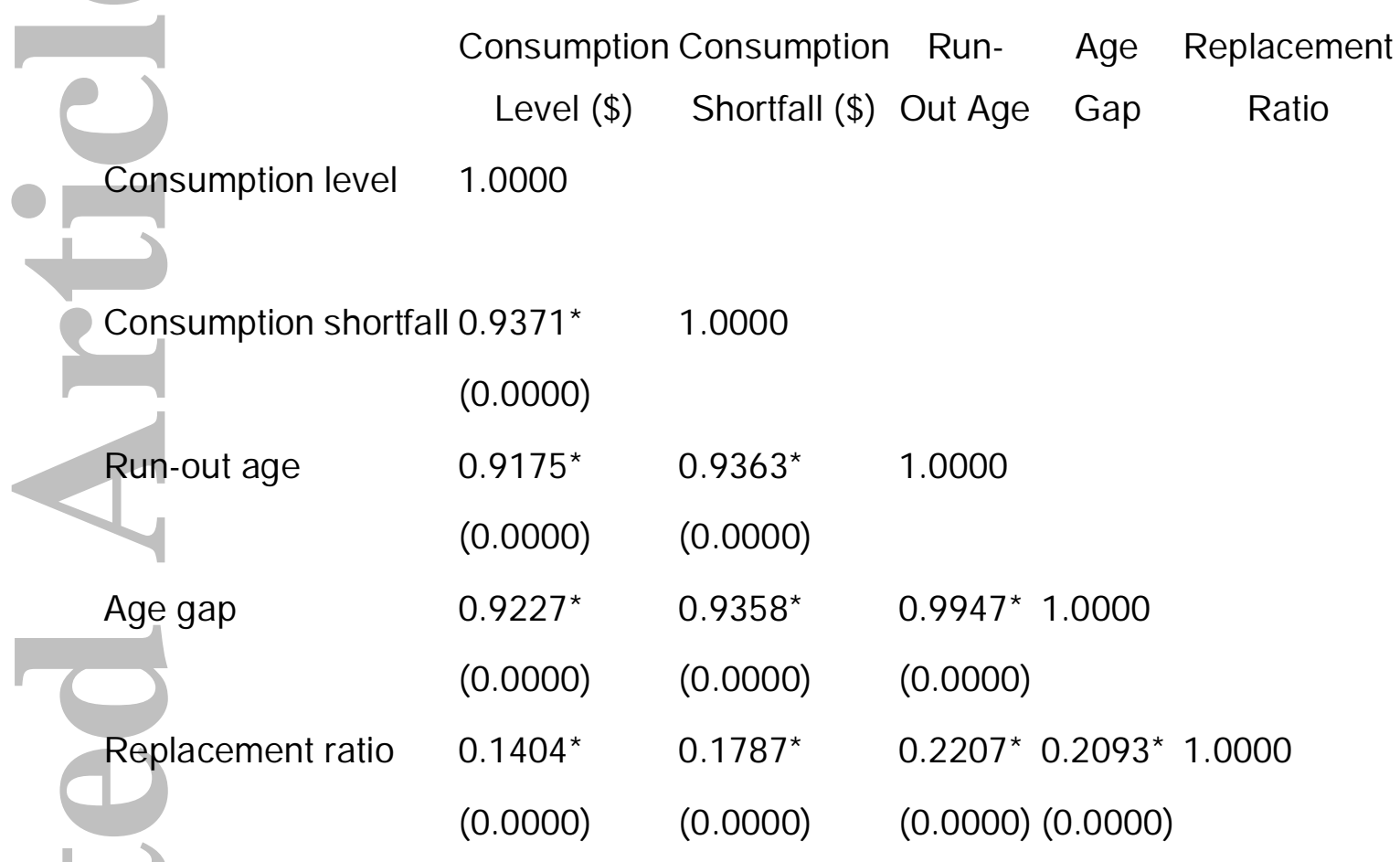

Note: $p$-values in parentheses.

Source: The Household, Income, and Labour Dynamics in Australia Survey (Wooden and Watson, 2007); own computations. 


\section{University Library}

\section{- M M N E R VA A gateway to Melbourne's research publications}

Minerva Access is the Institutional Repository of The University of Melbourne

Author/s:

MURAWSKI, C;Burnett, J;Davis, KEVIN;Wilkins, ROGER;Wilkinson, N

Title:

Measuring the Adequacy of Retirement Savings

Date:

2018-12-01

Citation:

MURAWSKI, C., Burnett, J., Davis, K. E. V. I. N., Wilkins, R. O. G. E. R. \& Wilkinson, N.

(2018). Measuring the Adequacy of Retirement Savings. Review of Income and Wealth, 64 (4), pp.900-927. https://doi.org/10.1111/roiw.12307.

Persistent Link:

http://hdl.handle.net/11343/293280 